\title{
REPRESENTASI BUDAYA MATRILINEAL MINANGKABAU DALAM FILM TENGGELAMNYA KAPAL VAN DER WIJCK
}

\author{
Trisnawati $^{1}$, Chelsy Yesicha ${ }^{2}$ \\ 1,2 Jurusan Ilmu Komunikasi Fakultas Ilmu Sosial dan Ilmu Politik Universitas Riau \\ Email: t_trisna@yahoo.com, chelsy.yesicha@ lecturer.unri.ac.id
}

\begin{abstract}
Abstrak
Film merupakan media komunikasi massa yang hingga kini masih mempunyai banyak peminat. Film menjadi salah satu alat representasi dari realitas kehidupan sehari-hari. Peneliti mengangkat film Tenggelamnya Kapal Van Der Wijck. Tenggelamnya Kapal Van Der Wijck menceritakan mengenai Zainuddin pemuda yatim piatu. Ayahnya orang Minangkabaudan Ibunya orang Makassar. Kemudian ia merantau dari tanah kelahiran ibunya Makassar ke kampung halaman ayahnya, Batipuh Sumatera Barat. Tetapi karena ibunya bukan orang Minangkabau ia mendapat perlakuan diskriminasi dari masyarakat setempat. Dia lalu jatuh hati dengan Hayati gadis Minangkabau kemenakan Penghulu Adat. Tetapi Zainuddin tidak diizinkan bersama Hayati karena adat. Metode penelitian ini menggunakan pendekatan kualitatif yang mengacu pada unit analisis semiotika Roland Barthes. Subjek penelitian ini adalah Budaya Matrilineal Minangkabau dengan objek penelitian Film Tenggelamnya Kapal Van Der Wijck. Teknik pengumpulan data dengan cara observasi, dokumentasi, dan studi kepustakaan. Lalu pada teknik analisis data menggunakan teknik analisis data semiotika Roland Barthes. Hasil Penelitian menunjukkan bahwa adanya keterkaitan antara scenescene yang diteliti dengan makna denotasi, konotasi, mitos dari Roland Barthes. Dan hasil penelitian juga menunjukkan bahwa terdapat representasi Budaya Matrilineal Minangkabau yaitu dalam film ini adat Minangkabau masih terlalu kaku, hanya dianggap Minang jika ibunya orang Minangkabau dan peran Mamak yang sangat kuat dalam keluarga dibandingkan ayah kandung sendiri. Mamak juga memiliki kewenangan penuh terhadap kemenakan.
\end{abstract}

Kata Kunci: Budaya, Film, Matrilineal. Minangkabau, Representasi

\begin{abstract}
Film is a media of mass communication that still have audiences until now. Film also become a media of life representation. Researcher lift a film entitled Tenggelamnya Kapal Van Der Wijck. Tenggelamnya Kapal Van Der Wijck is a film that tell about the orphan man, Zainuddin. He has a Minangnese father and a mother from Makassar. Then he decided to move to his father hometown, Batipuh West Sumatra. As a person of mix descent, he faces much discrimination from Minang conservatives. Although he loves Hayati, a Minangnese woman, the niece of local nobleman, he's not allowed to be with her because his background.The researcher method is cualitative that referring to semiotics analysis of Roland Barthes. The subject of the research is Minangkabau Matrilineal culture with research object is a Tenggelamnya Kapal Van Der Wijck Film. Data collection techniques using semiotic data analysis techniques by Barthes. On data validity techniques by extending participation and observational persistence. The result of this research show that scenes researched related with the meaning of denotation, connotation, and myth by Roland Barthes. And the result also shows that have the representation of Minangkabau Matrilineal Culture in Tenggelamnya Kapal Van Der Wijck that Minangkabau's culture is too strict, also people claimed as a Minangnese only if their mother is a Minangnese even though their father is a Minangnese. And Mamak (mother's brothers) has an authorization in their clan and to the nieces and nephews. And his authority is stronger than their own father.
\end{abstract}

Keywords: Culture, Film, Matrilineal, Minangkabau, Representation 


\section{PENDAHULUAN}

Dunia perfilman saat ini telah mampu merebut perhatian masyarakat. Terlebih setelah berkembangnya teknologi komunikasi massa yang dapat memberikan sarana bagi perkembangan dunia perfilman. Meskipun masih banyak bentuk-bentuk media massa lainnya, film memiliki efek khusus bagi para penontonnya. Dari puluhan sampai ratusan penelitian itu semua berkaitan dengan efek media massa film bagi kehidupan manusia, sehingga begitu kuatnya media mempengaruhi pikiran, sikap, dan tindakan penonton (Tamburaka, 2013:117). Namun dampak yang perlu diantisipasi adalah di samping memberi dampak positif, film tentu juga memiliki dampak negatif. Seperti terjadi pada beberapa film yang dibuat hanya untuk mencari keuntungan rumah produksi tersebut tanpa memperhatikan efek dari film yang dibuatnya.

Sebagaimana diketahui, film merupakan salah satu media komunikasi massa (Pranajaya,1999:11). Oleh karena itu film adalah medium komunikasi yang ampuh bukan saja untuk hiburan, tetapi juga untuk penerangan pendidikan (edukatif) secara penuh (Effendi, 2003:207). Film merupakan gambaran dari realitas, baik realitas budaya atau kehidupan masyarakat di sekitarnya. Film mencoba mengangkat persoalan yang ada di masyarakat maupun kebudayaan yang ada dalam masyarakat Indonesia.

Dari beberapa judul film yang mengangkat tema kebudayaan, film Tenggelamnya Kapal Van Der Wijck salah satu film yang sarat menampilkan budaya Indonesia. Tenggelamnya Kapal Van Der Wijck yang disutradarai oleh Sunil Soraya diadaptasi dari Novel karangan Buya Hamka berjudul sama yang terbit pada tahun 1938. Tenggelamnya Kapal Van Der Wijck mengisahkan persoalan adat yang berlaku di Minangkabau dan perbedaan latar belakang sosial yang menghalangi hubungan cinta sepasang kekasih hingga berakhir dengan kematian.

Tenggelamnya Kapal Van Der Wijck menceritakan seorang yatim piatu yang bernama Zainuddin. Ia ditinggal mati oleh kedua orang tuanya saat masih kecil. Kisah hidup dan percintaannya dipermasalahkan oleh masalah adat. Ayahnya orang Minang sedangkan ibunya orang Makassar. Ia dibesarkan oleh seseorang yang telah mengasuhnya dari kecil saat ayah ibunya masih hidup hingga ia ditinggal mati kedua orang tuanya sampai ia dewasa. Ditempuhnya tanah Minangkabau dengan cita-cita besar, cita-cita untuk menempuh tanah sang ayah, tanah tempat dibangsakan menurut istiadat dunia. Namun kedatangannya di sana ia tetap dipandang sebagai orang Makassar, sebagaimana di Makassar ia dipandang orang Padang (Hamka, 1982:219-220). Menurut adat Minang, seseorang dapat dikatakan orang Minang apabila ia mempunyai garis keturunan seorang ibu yang berpenduduk asli Minang.

Inti dari Film ini yang diadaptasi dari Novel karangan Buya Hamka adalah lika-liku kehidupan Zainuddin yang dipermasalahkan dengan suatu Adat Minangkabau yang sangat kental. Hingga kisahnya cintanya dengan gadis Minang bernama Hayati ditentang hebat oleh keluarga Hayati karena ia bukanlah seorang pemuda asal Minang asli. Menurut penduduk Minang, Zainuddin bukanlah orang Minang, karena yang berasal dari Minang adalah ayahnya, sedangkan ibunya berasal dari Makasar.

Tradisi Minangkabau memiliki tradisi yang unik jika dibandingkan dengan tradisi suku lain. Keunikan tradisi Minang terlihat dari sistem kekerabatan menurut jalur ibu (matrilineal). Sosok ibu menjadi dasar penentuan nama keluarga. Dalam tradisi Minang, nama keluarga berasal dari keluarga ibu. Di luar Minang biasanya seorang istri akan tinggal di rumah keluarga suami, sebaliknya Minang suami akan tinggal di rumah istri. Sedangkan urusan anak-anak si ibu mempercayakan kepada sang Paman (mamak), sang Mamak tersebung yang membimbing keponakan. Hubungan kekerabatan antara Mamak dan keponakan ialah hubungan antara seorang anak dengan saudara laki-laki ibunya. Bisa juga 
dicontohkan sebagai hubungan antara seorang anak laki-laki dengan anak-anak saudara perempuannya.

Penulis tertarik meneliti nilai adat Minangkabau karena adat yang terdapat dalam film ini berbeda dengan adat lain, serta adat itulah yang memicu permasalahan dalam film tersebut. Zainuddin tidak bisa bersama Hayati bukan karena Zainuddin mempunyai tabiat yang tidak terpuji, atau karena Zainuddin bodoh dan tidak berpengetahuan, atau karena Zainuddin tidak tampan, miskin ataupun yang lain. Yang menjadi persoalan ialah Zainuddin bukan orang Minangkabau, ibunya orang Makassar. Jika bukan orang minangkabau, maka derajadnya sebagai manusia akan berada setingkat di bawah derajad orang Minangkabau. Dipermasalahkan pula misalnya, seandainya nanti Zainuddin dan Hayati menikah dan punya anak ke mana anak itu harus berbako, karena dianggap keluarga (menurut garis ibu) dari Zainuddin tidak jelas dan bahkan tidak ada (di masyarakat Minangkabau).

Masalah diskriminasi sosial inilah yang dijadikan tema dalam Film Tenggelamnya Kapal Van Der Wijck. Masalah inilah yang melahirkan konflik-konflik, baik konflik antar tokoh (Zainuddin dengan Hayati, Zainuddin dengan mamak Hayati, Hayati dengan mamaknya), maupun konflik antara satu persoalan dengan persoalan yang lain. konflikkonflik itu pulalah yang melahirkan dan menggerakkan peristiwa-peristiwa (sehingga melahirkan plot).

\section{METODOLOGI PENELITIAN}

Penelitian ini menggambarkan metode penelitian kualitatif dengan penyajian analisa semiotika. Penelitian bertujuan untuk mendeskripsikan apa-apa yang saat ini berlaku di dalamnya terdapat upaya untuk mendeskripsikan, mencatat, menganalisis, dan menginterprestasikan kondisi-kondisi yang sekarang ini terjadi atau yang ada (Bungin, 2007:67). Penelitian ini dilaksanakan di Pekanbaru.

Subjek penelitian menurut Arikunto (2007:152) merupakan sesuatu yang sangat penting kedudukannya dalam penelitian, subjek penelitian harus ditata sebelum peneliti siap untuk mengumpulkan data. Subjek penelitian dapat berupa benda, hal, atau orang. Subjek dalam penelitian ini adalah scene-scene atau adegan yang terdapat dalam film Tenggelamnya Kapal Van Der Wijck Extended yang dirilis pada 11 September 2014 dengan durasi 195 menit. Objek penelitian adalah suatu atribut, sifat, atau nilai dari orang, objek atau kegiatan yang mempunyai variasi tertentu yang ditetapkan oleh peneliti untuk dipelajari dan kemudian ditarik kesimpulannya (Sugiyono, 2009: 38). Pada penelitian ini, objek yang akan diteliti budaya matrilineal minangkabau dan pesan moral dibalik film ini. Baik di dalamnya tercakup audio, visual gambar, properti, teks dialog, serta body language dari pemainnya.

Teknik pengumpulan data dilaksanakan dengan melalukan observasi, dokumentasi dan studi pustaka. Teknik analisis data selama di lapangan menggunakan teknik analisis oleh Roland Barthes melalui tiga kegiatan yang dilakukan yaitu menggali makna denotasi, konotasi dan mitos. Kualitas atau keabsahan data menggunakan teknik triangulasi.

\section{HASIL DAN PEMBAHASAN}

Dari rangkaian denotasi, konotasi, dan mitos yang diperoleh dalam film Tenggelamnya Kapal Van Der Wijck, peneliti memperoleh representasi dari subjek penelitian ini di mana dikatakan representasi adalah sesuatu yang merujuk pada proses yang dengannya realitas disampaikan dalam komunikasi, via kata-kata, bunyi, citra, atau kombinasinya (Fiske, 2004: 282). Representasi ini peneliti bagi dalam 3 unsur semiotika yang dikembangakan oleh Roland Barthes, yang pertama peneliti memperoleh hasil representasi dalam bentuk denotasi yang pengertiannya adalah denotasi merupakan makna 
sebenar-benarnya, yang disepakati secara sosial, yang rujukannya pada realitas, subjek penelitian ini yaitu pemuda bernama Zainuddin yang tidak dapat menikahi kekasihnya Hayati seorang gadis Minangkabau karena adat. Ayah Zainuddin orang Minangkabau dengan menganut sistem matrilineal, sementara ibunya orang Makassar yang menganut sistem patrilineal. Karena hal itu Zainuddin tidak direstui bersama Hayati karena status Zainuddin yang tidak dianggap orang Minangkabau.

Kekerabatan matrilineal di Minangkabau diikat dengan satu kesatuan yang ditarik dari satu garis keturunan perempuan. Bagi yang seketurunan seperti ini disebut satu suku (sesuku). Karena ia diambil dari garis ibu, maka ia bernama matrilineal (matri=keibuan, lineal=garis) (Yaswirman, 2013: 117).

Pertama, dalam film Tenggelamnya Kapal Van Der Wijck ini denotasi dari budaya matrilineal Minangkabau adalah status keturunan yang menurut garis ibu, atau matrilineal. Dalam ini seseorang tidak diakui sebagai orang Minangkabau walaupun ayahnya keturunan asli Minangkabau. Dari sudut pandang masyarakat Minangkabau orang yang seperti itu dianggap bukan orang Minangkabau karena ibunya bukan orang Minangkabau dan dari sudut pandang masyarakat Makassar Zainuddin juga bukan dianggap orang Makassar, karena Makassar menganut sistem kekerabatan patrilineal yaitu garis keturunan berasal dari ayah. Hal ini dapat dilihat dari data 2, 3, 4, dan 5 yang terlihat jelas mempermasalahkan status Zainuddin yang bukan orang Minangkabau.

Pada budaya matrilineal Minangkabau ada peraturan perkawinan, yaitu dianjurkan untuk menikah dengan sesame orang Minangkabau. Pernikahan beda suku tidak dilarang oleh agama, tetapi pada budaya Minangkabau pernikahan beda suku yaitu Minang dengan non-Minang akan mengakibatkan efek pengaburan garis keturunan. Hal ini terjadi jika lakilaki Minang menikah dengan perempuan non-Minang (Yaswirman, 2013: 302). Kasus ini terjadi pada Zainuddin. Status adatnya tidak jelas karena ayahnya yang orang Minang menikahi perempuan Makassar. Sedangkan garis keturunan atau suku merupakan hal yang sangan penting di Minangkabau.

Kedua, konotasi yang merupakan tanda yang penandanya mempunyai keterbukaan makna yang implisit, tidak langsung, dan tidak pasti, artinya terbuka kemungkinan terhadap penafsiran-penafsiran baru (Nawiroh, 2014: 28), dalam film ini budaya matrilineal Minangkabau menunjukkan Zainuddin tidak pantas bersanding dengan Hayati si Bungo Desa Batipuh kemenakan penghulu adat yang terpandang. Zainuddin diminta untuk memutuskan hubungannya dengan Hayati dan bahkan diminta untuk meninggalkan Desa Batipuh. Zainuddin dianggap tidak pantas untuk Hayati, akan memberi malu keluarga, malu kaum. Persoalan utamanya yaitu karena Zainuddin bukan orang Minangkabau, maka derajadnya dianggap lebih rendah. Hal ini dapat dilihat dari data 3, 4, 5 Mak Datuk, yaitu mamak dari Hayati marah besar saat mengetahui kedekatan Hayati dengan Zainuddin.

Ketiga, mitos yang didapat dari film ini di mana menurut Roland Barthes mitos berfungsi untuk mengungkapkan dan memberikan pembenaran bagi nilai-nilai dominan yang berlaku dalam suatu periode tertentu (Nawiroh, 2014: 28), berupa mamak (saudara laki-laki dari ibu) berperan penting dalam satu keluarga. Mamak berperan sebagai pelindung keluarga dan bertanggung jawab terhadap kemenakan. Apabila terjadi sesuatu di dalam kaumnya, yang akan turun langsung yaitu mamak, bukan orang tuanya. Mamak harus memberikan pengawasan terhadap kemenakannya, artinya mamak berkewajiban mengontrol dalam berbagai bidang seperti kesejahteraan, pendidikan, keamanan kemenakannya dalam kehidupannya sehari-hari.

Hal ini dapat dilihat dari scene 16, 18, 38 Mak Datuk menegur keras Hayati saat mengetahui hubungan Hayati dan Zainuddin. Kemudian diadakannya rapat ninik mamak untuk menentukan pasangan Hayati. Karena dalam waktu yang berdekatan datang lamaran 
dari Aziz kakak dari Khadijah sahabat Hayati dan lamaran dari Zainuddin. Ninik mamak sepakat untuk menerima lamaran dari Aziz yang dianggap lebih pantas, bermartabat, dan berketurunan Minangkabau asli. Sedangkan Zainuddin dianggap tidak jelas asal-usulnya yang tidak bersuku.

Representasi berkaitan dengan pembuatan makna, apa yang direpresentasikan kepada kita melalui media adalah makna-makna tentang dunia dan cara memahami media. Representasi budaya matrilineal Minangkabau dianalisis dengan menggunakan semiotika Roland Barthes. Representasi budaya matrilineal Minangkabau yang diteliti di sini adalah representasi suatu budaya yaitu yang menjadi pokok persoalan dalam film Tenggelamnya Kapal Van Der Wijck.

Dalam penelitian ini representasi budaya matrilineal Minangkabau dalam film Tenggelamnya Kapal Van Der Wijck ini terdapat kaitannya dengan teori yang dikemukakan oleh Roland Barthes, dengan menggunakan teori Roland Barthes tersebut peneliti dapat menemukan bagaimana representasi budaya matrilineal Minangkabau di dalam film Tenggelamnya Kapal Van Der Wijck.

Data 1, 2, 3, 4, 5, 6, 7, 8 menjelaskan dengan menggunakan semiotika Roland Barthes yaitu denotasi, konotasi, dan mitos untuk dapat melihat representasi budaya matrilineal Minangkabau melalui audio dan visual film Tenggelamnya Kapal Van Der Wijck. Denotasi, Budaya Matrilineal Minangkabau dalam film ini adalah status keturunan yang menurut garis ibu. Dalam hal ini seseorang tidak diakui sebagai orang Minangkabau jika ibunya bukan keturunan Minangkabau walau pun ayahnya orang Minangkabau. Konotasi, Budaya Matrilineal Minangkabau dalam film ini adalah Zainuddin tidak pantas bersanding dengan Hayati si Bungo Desa Batipuh kemenakan sang penghulu adat yang terpandang. Zainuddin akan membuat malu keluarga dan kaum karena bukan orang Minangkabau derajadnya dianggap lebih rendah. Mitos, Budaya Matrilineal Minangkabau dalam film ini adalah mamak (saudara laki-laki ibu) berperan penting dalam satu keluarga. Mamak harus memberikan pengawasan terhadap kemenakannya, artinya mamak berkewajiban mengontrol dalam berbagai bidang seperti kesejahteraan, pendidikan, keamanan, dan jodoh untuk kemenakannya.

Dalam film ini ada tiga poin penting yang menunjukkan representasi Budaya Matrilineal Minangkabau berdasarkan 1) Paruik, Organisasi dan Suku, 2) Hubungan kewajiban timbal balik antara mamak dengan kemenakan, 3) Makna falsafah Adat bersandi Syarak, Syarak bersandi Kitabullah.

\section{Paruik, Organisasi dan Suku}

Paruik adalah persekutuan hukum yang di dalam Bahasa Indonesia dapat kita samakan dengan keluarga. Hanya saja keluarga di sini harus diartikan keluarga besar yang dihitung dari garis ibu, sedangkan suami-suami dari anggota-anggota paruik tidaklah termasuk di dalamnya (Anwar, 1997: 9). Anggota-anggota dari suku masuk dan bertambah secara keharusan, oleh karena semua anak-anak yang dilahirkan ibunya langsung menurut suku ibunya, langsung menambah anggota suku ibunya, seperti anak-anak itu langsung menambah anggota-anggota jurai dan paruik ibunya. Hukum perkawinan juga termasuk ke dalam fungsi suku (Anwar, 1997: 60).

Dalam film tersebut budaya matrilineal Minangkabau status suku sangat dijunjung tinggi. Seorang anak bisa diakui sebagai orang Minangkabau jika ibunya orang Minangkabau. Walau pun ayahnya orang Minangkabau tetapi jika ibunya tidak orang Minangkabau anak itu tidak bisa dikatakan orang Minangkabau, karena arti matrilineal itu adalah garis keturunan menurut garis ibu. Hal inilah yang dialami Zainuddin, pemuda 
malang yang tidak diakui di tanah kelahiran ayahnya dan karena hal inilah ia tidak bisa menikah dengan Hayati si Bungo Desa Batipuh.

Pada data 2, 3, 4, 5 Mak Datuk dan Khadijah mengatakan bahwa Hayati tidak seharusnya dengan Zainuddin karena status suku Zainuddin yang tidak jelas, dianggap malu keluarga besar, dan kaum. Pada budaya matrilineal Minangkabau dianjurkan untuk menikah dengan sesama orang Minangkabau. Pernikahan beda suku memang tidak dilarang oleh agama, tetapi dalam budaya Minangkabau, pernikahan beda suku yaitu Minangkabau dengan non Minangkabau akan mengakibatkan efek pengaburan garis keturunan (Yaswirman, 2013: 302). Kasus ini yang terjadi pada Zainuddin.

Masalahnya bukanlah karena Zainuddin punya sifat yang jelek, atau Zainuddin tidak berpengetahuan atau miskin. Persoalannya adalah karena ia bukan orang Minangkabau. Derajadnya dianggap lebih rendah. Di sinilah masalahnya pembedaan derajad manusia tidak disebabkan oleh pembuktian manusia itu sendiri, pengetahuan atau pun amal, tetapi sesuatu yang telah ditetapkan sebelumnya oleh keturunan asal-usul. Keturunan dan asal-usul seseorang jauh lebih penting dari apa dan bagaimana perbuatan, perangai, pengetahuan dan amal. Sebagai individu, Zainuddin adalah orang yang baik, memiliki sifat dan perilaku terpuji, alim dan berpengetahuan, sopan, dan punya perasaan halus. Akan tetapi ia tidak bisa diterima untuk dijodohkan dengan Hayati karena ia dianggap bukan orang Minangkabau. Derajadnya rendah karena kebetulan ibunya bukan orang Minangkabau.

\section{Hubungan kewajiban timbal balik antara mamak dengan kemenakan}

Berdasarkan uraian yang di atas mamak adalah saudara laki-laki ibu. Ia memiliki kewenangan yang besar terhadap kemenakannya. Apabila dalam anggota paruik telah bertambah banyak dan berkembang, maka paruik itu akan membelah diri menjadi unit-unit ini disebut jurai dan ada juga yang menyebutnya toboh. Ia merupakan kesatuan keluarga kecil yang sadapua (sedapur). (https://majalahsaran.wordpress.com/2009/08/30/strukturmasyarakat-minangkabau/amp/ diakses pada tanggal 7 Mei 2018).

Demikianlah mamak tadi berkewajiban memelihara anggota jurainya istimewa menjaga wanita-wanita serta anak-anak yang belum aqil baliq serta dia juga harus memperhatikan keselamatan harto pusako dari jurainya yang tidak lagi dipunyai bersamasama dengan cabang-cabang yang lain dari paruik. Mamak adalah pelaksana dari kepentingan-kepentingan material keluarga baik pun terhadap wanita-wanita dan anak-anak yang belum dewasa maupun terhadap orang-orang yang telah tua yang tidak kuat lagi mencari nafkah, juga terhadap anggota-anggotanya yang ditimpa kemalangan atau yang sedang sakit (Anwar, 1997: 84). Mamak harus mencarikan jodoh kamanakan-kamanakannya yang perempuan tepat pada waktunya dan setelah persesuaian dengan segenap anggota keluarga degan mamak juga diputuskan siapakah yang diambil sebagai urang sumando. (Anwar, 1997: 85)

Film Tenggelamnya Kapal Van Der Wijck menunjukkan bahwa mamak memiliki otoritas penuh dalam memutuskan jodoh Hayati (terlihat pada data 1, 4, 5, 6). Pada data 6 juga menampilkan peranan musyawarah ninik mamak yang digelar dalam menentukan jodoh Hayati. Dari musyawarah tersebut dipilihlah Aziz dari Padang Panjang karena Aziz orang Minangkabau asli, berketurunan. Hal ini yang menunjukkan kekakuan budaya matrilineal Minangkabau pada saat itu. Minangkabau berdasarkan garis ibu, namun yang berkuasa di dalam kesatuan-kesatuan tersebut selalu orang laki-laki dari garis ibu, hanya saja kekuasaan selalu didasarkan atas mufakat seperti bunyi pepatah Minang "kemenakan barajo ke mamak, mamak barajo kamupakat" (Anwar, 1997: 11). 


\section{Makna Falsafah Adat Bersandi Syarak, Syarak Bersandi Kitabullah}

Kedinamiasan hukum adat Minangkabau menjadikan ia sangat respons terhadap perkembangan sosial. Pertentangan-pertentangan yang begitu tajam antara hukum adat dan hukum Islam dalam lapangan hukum keluarga (Radjab, 1954: 86).

Syarak merupakan ajaran islam yang tercantum dalam Kitabullah, namun dalam budaya Minangkabau sekitar tahun 1930-an di mana setting film tersebut dibuat, syarak lebih memakai kaidah-kaidah adat istiadat. Hal inilah menjadi salah satu alasan Hamka mengkritik Minangkabau dalam novel Tenggelamnya Kapal Van Der Wijck. Budaya matrilineal yang masih kaku yang memegang teguh adat tanpa mempertimbangkan hal lain. Pepatah Minangkabau yaitu Adat bersandi syarak, syarak bersandikan Kitabullah. Hal ini menurut Yasirman (2013) mengandung arti bahwa antara adat dan syarak saling membutuhkan dan tak dapat dipisahkan. Sedangkan dalam agama Islam kita tidak dapat membeda-bedakan seseorang hanya dari suku saja, tetapi dari segi perbuatan, perilaku, dan akidahnya. Adat Minangkabau mempunyai pepatah adat bersandi syara', syara' bersandikan Kitabullah, namun dalam film Tenggelamnya Kapal Van Der WIjck berbenturan dengan kenyataan. Secara tidak langsung Hamka mengatakan bahwa cinta Hayati dan Zainuddin itu patutnya diperbolehkan. Karena dalam agama tidak ada yang melarang pernikahan hanya karena suku. Kejadian tersebut yang menandakan kesalahan Datuk Hayati yang seakan meletakkan adat di atas kitabullah. Tidak peduli apakah Zainuddin pemuda yang sopan, berperilaku baik tetapi mementingkan asal-usul adat.

Dalam Film Tenggelamnya Kapal Van Der Wijck, harga diri seseorang diakui jika ia berketurunan Minangkabau. Zainuddin yang memiliki akhlak yang baik tetapi tetap dianggap derajadnya lebih rendah dan tidak diakui status Minangkabaunya. Zainuddin justru diakui sebagai laki-laki Minangkabau ketika ia sudah kaya-raya dan sukses di Surabaya.

Representasi budaya Matrilineal Minangkabau menjunjung tinggi garis keturunan ibu, otoritas mamak dalam menentukan jodoh untuk kemenakan perempuan sangat besar tanpa menimbang perasaan Hayati, dalam film Tenggelamnya Kapal Van Der Wijck memegang teguh syarak adat justru harga diri Zainuddin bersuku Minangkabau baru diakui ketika ia sudah sukses.

\section{PENUTUP}

Hasil penelitian dan pembahasan diatas menghasilkan kesimpulan mengenai Representasi Budaya Matrilineal Minangkabau dalam Film Tenggelamnya Kapal Van Der Wijck sebagai berikut:

1 Denotasi, Budaya Matrilineal Minangkabau dalam film ini adalah status keturunan yang menurut garis ibu. Dalam hal ini seseorang tidak diakui sebagai orang Minangkabau jika ibunya bukan keturunan Minangkabau walau pun ayahnya orang Minangkabau. Konotasi, Budaya Matrilineal Minangkabau dalam film ini adalah Zainuddin tidak pantas bersanding dengan Hayati si Bungo Desa Batipuh kemenakan sang penghulu adat yang terpandang. Zainuddin akan membuat malu keluarga dan kaum karena bukan orang Minangkabau derajadnya dianggap lebih rendah. Mitos, Budaya Matrilineal Minangkabau dalam film ini adalah mamak (saudara laki-laki ibu) berperan penting dalam satu keluarga. Mamak harus memberikan pengawasan terhadap kemenakannya, artinya mamak berkewajiban mengontrol dalam berbagai bidang seperti kesejahteraan, pendidikan, keamanan, dan jodoh untuk kemenakannya.

2 Representasi budaya Matrilineal Minangkabau menjunjung tinggi garis keturunan ibu, otoritas mamak dalam menentukan jodoh untuk kemenakan perempuan sangat besar tanpa menimbang perasaan Hayati, dalam film Tenggelamnya Kapal Van Der Wijck 
memegang teguh syarak adat justru harga diri Zainuddin bersuku Minangkabau baru diakui ketika ia sudah sukses.

\section{REFERENSI}

\section{Buku}

Agee, dkk. 2001. Introduction to Mass Communication. New York: Longman.

Amir. 2011. Harato Pusako Tinggi \& Pencaharian. Jakarta: Citra Harta Prima.

Anwar, Chairul. 1997. Hukum Adat Indonesia Meninjau Hukum Adat Minangkabau. Jakarta: Rineka Cipta.

Ardianto, dkk. 2009. Komunikasi Massa: Suatu Pengantar. Bandung: Simbiosa Rekatama Media.

Arikunto, Suharsimi. 2007. Prosedur Penelitian Suatu Pendekatan Praktik. Jakarta: Rineka Cipta.

Berger, dkk. 1990. Tafsiran Sosial atas Kenyataan Risalah tentang Sosiologi Pengetahuan. Jakarta: LP3ES.

Bungin, Burhan. 2007. Penelitian Kualitatif. Jakarta: Kencana.

Canggara, Hafied H. 2006. Pengantar Ilmu Komunikasi. Jakarta: PT. Raja Grafindo Persada.

Danesi, Marcel. 2010. Pengantar Memahami Semiotika Media. Yogyakarta: Jalasutra.

Dominick, Joseph R. 2000. The Dynamics of Mass Communication. New York: Random House.

Eriyanto. 2002. Analisis Framing: Konstruksi, Ideologi, Politik Media. Yogyakarta: Remaja Rosdakarya.

Effendy, Onong. Uchjana. 2004. Dinamika Komunikasi. Bandung: Remaja Rosdakarya.

Esten, M. 1987. Kesusastraan Pengantar Teori dan Sejarah. Bandung: Angkasa.

Fiske, J. 2004. Cultural and Communication Studies. Yogyakarta: Jalasutra.

Habermas, Jurgen. 1973. Legittimation Crisis. Boston: Beacon Press.

Hamad, Ibnu. 2004. Konstruksi Realitas Politik dalam Media Massa (Sebuah Studi Critical Discourse Analysis terhadap Berita-Berita Politik). Jakarta: Granit.

Hamka. 1986. Tenggelamnya Kapal Van Der Wijck. Jakarta: Bulan Bintang.

Hardiman, Budi F. 1993. Menuju Masyarakat Komunikatif: Ilmu, Masyarakat, Politik, dan Postmodernism Menurut Jurgen Habermas. Yogyakarta: Kanisius.

Heraty, Tutty. 2002. Aku Dalam Budaya. Jakarta: Pustaka Jaya.

Jumroni. 2006. Metode-metode Penelitian UIN Syarif Hidayatullah. Jakarta: Jakarta Press.

Koentjaraningrat. 2007. Manusia dan Kebudayaan di Indonesia. Jakarta: Djambatan.

Kriyantono, Rachmat. 2006. Riset Komunikasi. Jakarta: Kencana.

Kurniawan. 2001. Semiologi Roland Barthes. Magelang: Tera.

Marcuse, Herbert. 2000. Manusia Satu Dimensi. Yogyakarta: Bentang.

Maryani, Eni. 2011. Media dan Perubahan. Bandung: Remaja Rosdakarya.

McQuail, Dennis. 2005. Teori Komunikasi Massa. Jakarta: Erlangga.

Mulyana, Deddy dan Jalaluddin Rakhmat. 2006. Panduan Berkomunikasi dengan Orangorang Berbeda Budaya. Bandung: Remaja Rosdakarya.

Nawawi, Ismail. 2012. Metode Penelitian Kualitatif Teori dan Aplikasi Interdisipliner. Jakarta: Dwi Putra Pustaka Jaya.

PaEni, Mukhlis. 2009. Sejarah Kebudayaan Indonesia. Jakarta: Rajawali Pers.

Pawito. 2007. Penelitian Komunikasi Kualitatif. Yogyakarta: Pelangi Aksara.

Pranajaya, Adi. 1999. Film dan Masyarakat: Sebuah Pengantar. Jakarta: BP SDM Citra Pusat Perfilman Haji Usmar Ismail.

Ruslan, Rusady. 2010. Manajemen Public Relations dan Media Komunikas, Konsepsi dan Aplikasi. Jakarta: Rajawali Pers. 
Sarwono, Jonathan. 2006. Metode Penelitian Kuantitatif dan Kualitatif. Yogyakarta: Graha Ilmu.

Sobur, Alex. 2004. Semiotika Komunikasi. Bandung: PT Rosdakarya. .2009. Analisis Teks Media. Bandung: PT Rosdakarya.

Sudjiman, Panuti. 1986. Kamus Istilah Sastra. Jakarta: Gramedia.

Sugiarto. 2004. Teknik Sampling Data. Jakarta: Gramedia.

Sugiyono. 2009. Metode Penelitian Kuantitatif Kualitatif dan R\&D. Bandung: Alfabeta.

Sumadira. 2005. Media Komunikasi. Jakarta: Yayasan Obor Indonesia.

Tamburaka. 2013. Literasi Media. Jakarta: PT. Raja Grafindo Persada.

Yaswirman. 2011. Hukum Keluarga Karakteristik dan Prospek Doktrin Islam dan Adat dalam Masyarakat Matrilineal Minangkabau. Jakarta: Raja Grafindo Persada.

\section{Internet}

https://mersi.wordpress.com/2008/08/12/makalah-keminangkabauan-mamak-dan kemenakan/

http://neozonk.wordpress.com/2012/09/17/film-sebagai-mediapembelajaran/

http://movieholictasikmalaya.blogspot.co.id/2014/09/editorial-fakta-menarik-seputar.html

http://tabloidkabarfilm.com/profilm/dia/498/498.html

https://twitter.com/sorayafilms/status/351804307118624772

https://id.wikipedia.org/wiki/Tenggelamnya_Kapal_Van_der_Wijck_(film) 